\title{
TarMed-Information / Informations sur le TarMed
}

Die Seminarteilnehmer erhalten Einblick in den neuen Tarif "TarMed" und Gelegenheit, in einem Workshop Fallbeispiele zu lösen. Für FMH-Mitglieder ist die Teilnahme am Seminar-Unterricht kostenlos, für NichtFMH-Mitglieder wird ein Beitrag von Fr. 300.- erhoben.

Seminar/séminaire:

$\begin{array}{lllll}\text { Nr. 21 } & \text { Freitag, 7. April 2000 } & \text { Zürich } & 9.00-17.00 \mathrm{Uhr} & \text { Inter-Continental } \\ \text { Nr. 22 } & \text { Samstag, 8. April 2000 } & \text { Zürich } & 9.00-17.00 \mathrm{Uhr} & \text { Inter-Continental } \\ \text { No 24 } & \text { Jeudi, 25 mai 2000 } & \text { Fribourg } & 9.00-17.00 \mathrm{~h} & \text { Au Parc Hôtel } \\ \text { No 25 } & \text { Vendredi, 26 mai 2000 } & \text { Fribourg } & 9.00-17.00 \mathrm{~h} & \text { Au Parc Hôtel } \\ \text { Nr. 26 } & \text { Mittwoch, 19. April 2000 } & \text { Bern } & 9.00-17.00 \mathrm{Uhr} & \text { Hotel Schweizerhof } \\ \text { Nr. 27 } & \text { Donnerstag, 20. April 2000 } & \text { Bern } & 9.00-17.00 \mathrm{Uhr} & \text { Hotel Schweizerhof }\end{array}$

\section{Anmeldung/Inscription}

Ich melde mich hiermit für das folgende Seminar an / Je m'inscris au séminaire suivant:

Seminar Nr. $/ n^{\circ}$ du séminaire

Name / nom $\quad$ Vorname / prénom

\begin{tabular}{ll}
\hline Strasse / rue & PLZ/Ort NPA/lieu
\end{tabular}

Tel. privat / tél. privé

Tel. Praxis/Spital / tél. cabinet/hôpital

Datum / date Unterschrift / signature

Telefonische Auskünfte erhalten Sie unter Tel. 0419250077 bei Frau S. Lichtsteiner Renseignements complémentaires: Mme S. Lichtsteiner, tél. 0419250077

Die Anmeldung ist möglich per Telefon, Post, E-mail oder Fax an:

Vous pouvez vous inscrire par téléphone, par bulletin d'inscription, par fax ou e-mail:

FMH Tarifdienst, Frau S. Lichtsteiner, Burghöhe 1, Postfach 246, 6208 Oberkirch, Fax 04192105 86, E-mail fmhtarif@hin.ch

Aus organisatorischen Gründen bitten wir Sie, sich frühzeitig anzumelden. Die Teilnehmerzahl ist begrenzt.

Pour des raisons d'organisation, nous vous prions de vous inscrire le plus tôt possible. Le nombre de participants est limité. 